Recent NHS England guidance recommends screening all emergency hospital admissions on admission followed by a single repeat, for those testing negative, between 5 and 7 days after admission. ${ }^{5}$ Our data demonstrate that healthcare-associated COVID-19 has contributed an important number of cases patients during the height of a pandemic. Sequential screening of non-COVID-19 hospitalized patients beyond this, possibly on a weekly basis up to 14 days after hospital discharge, may prove beneficial in further reducing the threat posed by SARS-CoV-2. Further validation of proposed definitions is required and according to the evolution of CDI definitions, amendments are likely.

Financial support. No financial support was provided relevant to this article.

Conflict of interests. All authors report no conflicts of interest relevant to this article.

\section{References}

1. Praet: Van Praet JT, Claeys B, Coene AS, Floré K, Reynders M. Prevention of nosocomial COVID-19: another challenge of the pandemic.
Infect Control Hosp Epidemiol 2020 [Epub ahead of print]. doi: 10.1017/ ice.2020.166.

2. Vanhems P. Fast nosocomial spread of SARS-CoV2 in a French geriatric unit Lyon Study Group on COVID-19 infection. Infect Control Hosp Epidemiol 2020 [Epub ahead of print]. doi: 10.1017/ice.2020.99.

3. COVID-19: infection prevention and control guidance. Public Health England website. https:/assets.publishing.service.gov.uk/government/uploads/ system/uploads/attachment_data/file/886215/COVID-19_Infection_ prevention_and_control_guidance_complete.pdf. Published January 10, 2020. Accessed May 18, 2020.

4. Clostridium difficile infection objectives for NHS organisations in 2019/20 and guidance on the intention to review financial sanctions and sampling rates from 2020/21 improvement. National Health Service England and National Health Improvement website. https://improvement.nhs.uk/ documents/808/CDI_objectives_for_NHS_organisations_in_2019_12 March.pdf. Published February 2019. Accessed May 18, 2020.

5. Operating framework for urgent and planned services in hospital settings during COVID-19. National Health Service England and National Health Improvement website. https:/www.england.nhs.uk/coronavirus/wp-content/ uploads/sites/52/2020/05/Operating-framework-for-urgent-and-plannedservices-within-hospitals.pdf. Published May 14, 2020. Accessed May 18, 2020.

\title{
Lack of transparency during the COVID-19 pandemic: Nurturing a future and more devastating crisis
}

\author{
Alain Braillon PhD MD ${ }^{1}$ (1) \\ ${ }^{1}$ Retired
}

"Collaboration is a key part of the success of any organization, executed through a clearly defined vision and mission and based on transparency and constant communication." Dinesh Paliwal. (https://en.wikipedia.org/ wiki/Dinesh_Paliwal)

To the Editor-The editor must be commended for having provided to Rahimi et $\mathrm{al}^{1}$ the opportunity to pledge transparency during the COVID-19 crisis, a major issue that has been overlooked in scholarly journals. This issue has two aspects, most concrete.

First, healthcare professionals have faced bullying when speaking out in the media about their real-life experiences of the COVID-19 crisis as they faced basic resources shortage or bureaucratic barriers precluding adequate care or even protecting themselves. In The New York Times, Scheiber and Rosenthal reported that nurses and doctors were bullied for speaking out. ${ }^{2}$ Similarly, in the United Kingdom, hospital professionals were gagged for voicing concerns about shortages of equipment to protect against coronavirus. ${ }^{3}$ This occurrence is most frightening because in the United Kingdom the culture of transparency is an old one and has even been strengthened by a comprehensive framework of legal protections: the Employment Rights Act 1996, amended as Public Interest Disclosure Act 1998, and the Defamation Act of 2013. In other European countries, no

Author for correspondence: Alain Braillon, E-mail: braillon.alain@gmail.com

Cite this article: Braillon A. (2021). Lack of transparency during the COVID-19 pandemic: Nurturing a future and more devastating crisis. Infection Control \& Hospital Epidemiology, 42: 497-498, https://doi.org/10.1017/ice.2020.271 protections exist for whistleblowers, and the motto seems to be "Silence is golden"!

This issue also extends to scientific committees advising governments. In Great Britain, the government deliberately kept secret the list of participants in its committee of scientific experts. ${ }^{4}$ In France, the Haut Conseil de la Santé Publique (High Council of Public Health), the expert body of the Ministry of Health for the French government, issued 4 dozen reports about COVID-19. As a member, when recruited, I had to sign a form swearing I would respect the "duty of reserve" regarding the content of meetings. This issue is not a theoretical one: I was forced to resign (October 3, 2018) from Public Health France's scientific committee after a written threat of being sued for such a breach if I refused to resign because whistleblowing by a civil servant is a specific criminal offense in France (Law 83-634, Article 26). This situation contrasts with that the United States where the Lloyd-La Follette Act of 1912 protects civil servants who criticize superiors from official retribution.

In 1998, Söderlund summarized the challenges faced by healthcare systems "protecting against catastrophic illness events," "improving allocative efficiency and equity of access to services," and "combating cost escalation," among many key issues." Setting transparent and fair rules is a mandatory prerequisite for confidence and effectiveness. Old democracies are deliberately breaching their most basic principle. The crisis is before us.

Acknowledgments.

Financial support. No financial support was provided relevant to this article. 
Conflicts of interest. The author reports that he is an unpaid member of the Haut Conseil de la Santé Publique (High Council of Public Health), the expert body of the Ministry of Health for the French government.

\section{References}

1. Rahimi F, Talebi Bezmin Abadi A. Transparency and information sharing could help abate the COVID-19 pandemic. Infect Control Hosp Epidemiol 2020 Apr 22 [Epub ahead of print]. doi: 10.1017/ice. 2020.174 .

2. Scheiber N, Rosenthal BM. Nurses and doctors speaking out on safety now risk their job. New York Times website. https://www.nytimes.com/2020/04/ 09/business/coronavirus-health-workers-speak-out.html. Published April 9, 2020. Accessed May 16, 2020.

3. Campbell D. NHS staff "gagged" over coronavirus shortages. The Guardian website. https://www.theguardian.com/society/2020/mar/31/nhs-staffgagged-over-coronavirusprotective-equipment-shortages. Published March 31, 2020. Accessed May 16, 2020.

4. Stewart $\mathrm{H}$. We will not publish who is on scientific advisory group, says Raab. The Guardian website. https:/www.theguardian.com/world/2020/apr/26/ raab-warns-britons-of-risk-of-second-spike-in-coronavirus-outbreak Published April 26, 2020. Accessed May 16, 2020.

5. Söderlund N. Possible objectives and resulting entitlements of essential healthcare packages. Health Policy 1998;45:195-208.

\title{
RT-PCR tests for SARS-CoV-2 processed at a large Italian Hospital and false-negative results among confirmed COVID-19 cases
}

\author{
Francesca Valent PhD (10, Anna Doimo MD, Giada Mazzilis MD and Corrado Pipan MD \\ Institute of Hygiene and Clinical Epidemiology, University Hospital of Udine, Udine, Italy
}

To the Editor - In Italy, the first autochthonous case of coronavirus disease 2019 (COVID-19) was detected on February 21, 2020. By mid April 2020, >15,000 persons had been infected in the country and $>20,000$ had died. ${ }^{1}$ More than 1 million upper respiratory specimens were collected through nasopharyngeal or oropharyngeal swabs ${ }^{2}$ for infection confirmation or screening purposes. The proportion of the population with confirmed infection varies across the 20 Italian regions, as does the number of swabs collected per population unit. ${ }^{2}$

Real-time reverse-transcriptase polymerase chain reaction (RT-PCR) is used to test for severe acute respiratory coronavirus virus 2 (SARS-CoV-2) in the specimens collected through swabs, as recommended by the World Health Organization for clinical management and outbreak control purposes. ${ }^{3}$ It is currently the gold standard for the etiological diagnosis of SARS-CoV-2 infection.

However, RT-PCR may fail to identify infected persons. A Chinese study of 610 hospitalized COVID-19 cases revealed that results of RT-PCR varied within the same patients throughout their diagnostic and therapeutic course and hypothesized a high rate of false-positive tests. ${ }^{4}$ False-positive tests were also suspected by Xiao et $\mathrm{al}^{5}$ in their study of 70 COVID-19 patients.

The University Hospital of Udine, Italy, serving a population of 530,000 , has offered RT-PCR tests for detecting SARS-CoV-2 since the beginning of March, when the first COVID-19 case was suspected in the hospital catchment area. Swabs are collected from hospitalized or symptomatic persons, from asymptomatic close contacts of confirmed cases, identified through contact tracing, or for screening purposes. We investigated the possibility that a person with COVID-19 confirmed by a positive RT-PCR test on an upper respiratory specimen collected though swab had a subsequent false-negative test in the first 6 weeks of outbreak, analyzing

Author for correspondence: Francesca Valent, E-mail: francesca.valent@asufc. sanita.fvg.it

Cite this article: Valent F, et al. (2021). RT-PCR tests for SARS-CoV-2 processed at a large Italian Hospital and false-negative results among confirmed COVID-19 cases. Infection Control \& Hospital Epidemiology, 42: 498-499, https://doi.org/10.1017/ ice. 2020.290
Table 1. Age Distribution of COVID-19 Cases Identified Through RT-PCR Test for SARS-COV-2 on Upper Respiratory Specimens Collected Through Nasal Swabs, University Hospital of Udine, Italy, Between March 1, 2020, and April 12, 2020

\begin{tabular}{lccc} 
Age & Cases With at Least \\
Group & $\begin{array}{c}\text { CoviD-19 } \\
\text { Cases }\end{array}$ & $\begin{array}{c}\text { Cases with False-Negative } \\
\text { Positive Test, } \\
\text { No. }(\%)\end{array}$ & $\begin{array}{c}\text { Result of All With at Least } \\
\text { 2 Additional Exams, } \\
\text { No. (\%) }\end{array}$ \\
\hline $0-14$ & 11 & $7(63.6)$ & $3(42.9)$ \\
\hline $15-44$ & 207 & $138(66.7)$ & $26(18.8)$ \\
\hline $45-64$ & 280 & $187(66.8)$ & $37(19.8)$ \\
\hline $65-74$ & 120 & $58(48.3)$ & $13(22.4)$ \\
\hline $75-89$ & 162 & $37(22.8)$ & $3(8.1)$ \\
\hline$\geq 90$ & 80 & $6(7.5)$ & $2(33.3)$ \\
\hline
\end{tabular}

the anonymous administrative database of the Virology Laboratory of the University Hospital of Udine, where subjects are identified by an anonymous univocal stochastic key. For patients with at least 1 positive test (COVID-19 cases), we assessed false-negative tests, defined as negative tests between 2 positive tests.

From March 1 to April 12, our laboratory processed 15,702 RT-PCT tests on 10,482 people, and we identified 860 new COVID-19 patients (Table 1). The daily number of exams increased progressively exceeding 1,000 by April 9, whereas the proportion of those resulting positive peaked on March $17(23.5 \%)$ and then progressively decreased.

Subjects with $>1$ swab collection were 2,949 (28.1\%). The proportion increased from $25.1 \%$ among 9,658 subjects with initial negative exam, to $37.3 \%$ among 59 with initial invalid exam, to $65.9 \%$ among 765 with initial positive result $\left(\chi^{2}\right.$ test, $\left.P<.0001\right)$. The median times from first to second exam were 7,1 , and 11 days, respectively.

Of 860 COVID-19 cases, 433 had at least 2 additional swabs after the first positive result. The likelihood of having at least 2 additional swabs decreased significantly among the elderly $\left(\chi^{2}\right.$ test, $\left.P<.0001\right)$ (Table 1$)$. Of COVID-19 cases with at least 